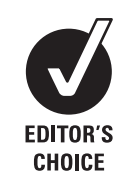

- The full version of this article is available online only at http:// ard.bmj.com/content/vol68/ issue1

For numbered affiliations see end of article

Correspondence to: Dr W Zhang, Academic Rheumatology, University of Nottingham, Clinical Sciences Building, City Hospital, Nottingham NG5 1PB, UK; weiya.zhang@nottingham.ac.uk

Accepted 28 January 2008 Published Online First 4 February 2008

\title{
EULAR evidence-based recommendations for the diagnosis of hand osteoarthritis: report of a task force of ESCISIT
}

\author{
W Zhang, ${ }^{1}$ M Doherty, ${ }^{1}$ B F Leeb, ${ }^{2}$ L Alekseeva, ${ }^{3}$ N K Arden, ${ }^{4} \mathrm{~J}$ W Bijlsma, ${ }^{5}$ F Dincer, ${ }^{6}$ \\ K Dziedzic, ${ }^{7} \mathrm{H}$ J Hauselmann, ${ }^{8} \mathrm{P}$ Kaklamanis, ${ }^{9} \mathrm{M}$ Kloppenburg, ${ }^{10} \mathrm{~L}$ S Lohmander, ${ }^{11}$ \\ E Maheu, ${ }^{12}$ E Martin-Mola, ${ }^{13}$ K Pavelka, ${ }^{14}$ L Punzi, ${ }^{15}$ S Reiter, ${ }^{16} \mathrm{~J}$ Smolen, ${ }^{17}$ \\ $\mathrm{G}$ Verbruggen, ${ }^{18}$ | Watt, ${ }^{19}$ | Zimmermann-Gorska ${ }^{20}$
}

\section{ABSTRACT}

Objectives: To develop evidence-based recommendations for the diagnosis of hand osteoarthritis (OA).

Methods: The multidisciplinary guideline development group, representing 15 European countries, generated 10 key propositions regarding diagnosis using a Delphi consensus approach. For each recommendation, research evidence was searched for systematically. Whenever possible, the sensitivity, specificity and likelihood ratio (LR) were calculated; relative risk and odds ratios were estimated for risk factors for hand OA. Quality of evidence was categorised using the European League Against Rheumatism (EULAR) hierarchy, and strength of recommendation was assessed by the EULAR visual analogue scale.

Results: Diagnostic topics included clinical manifestations, radiographic features, subgroups, differential diagnosis, laboratory tests, risk factors and comorbidities. The sensitivity, specificity and $L R$ varied between tests depending upon the cut-off level, gold standard and controls. Overall, no single test could be used to define hand $\mathrm{OA}$ on its own $(\mathrm{LR}<10)$ but a composite of the tests greatly increased the chance of the diagnosis. The probability of a subject having hand OA was $20 \%$ when Heberden nodes alone were present, but this increased to $88 \%$ when in addition the subject was over 40 years old, had a family history of nodes and had joint space narrowing in any finger joint.

Conclusion: Ten key recommendations for diagnosis of hand $\mathrm{OA}$ were developed using research evidence and expert consensus. Diagnosis of hand OA should be based on assessment of a composite of features.

Hand osteoarthritis (OA) is highly prevalent. ${ }^{2}$ It occurs commonly, though not exclusively, in the context of generalised $\mathrm{OA},{ }^{3-5}$ and can result in considerable disability. ${ }^{67}$ Although a number of criteria have been used to define hand $\mathrm{OA}(\mathrm{HOA}){ }^{8-}$

${ }^{11}$ diagnosis presents certain difficulties due to the large number of joints involved, the broad spectrum of disease severity and possible subsets (table 1).

After developing evidence-based recommendations for management of knee $\mathrm{OA},{ }^{12}{ }^{13}$ hip $\mathrm{OA}^{14}$ and $\mathrm{HOA},{ }^{15}$ the EULAR OA Task Force agreed that issues relating to diagnosis of HOA merit their own consideration. Therefore the following recommendations were developed using an evidence-based format involving a systematic review of research evidence and expert consensus. ${ }^{16}$

\section{METHODS}

A multidisciplinary guideline development group, comprising 21 OA experts from 15 European countries, was commissioned by the EULAR Standing Committee for International Clinical Studies Including Therapeutics (ESCISIT). Each participant contributed independently up to 10 propositions related to key clinical aspects in diagnosis of HOA. Consensus was reached using the Delphi technique. ${ }^{15}$ As before ${ }^{15}{ }^{17}$ a systematic search of the literature published between January 1945 and January 2006 was undertaken; the search for $\mathrm{HOA}^{15}$ was combined with searches for each diagnostic issue ${ }^{17}$ (see extended version of this article online at http://ard.bmj.com for full search details). The best available evidence was used to support the recommendations according to the EULAR hierarchy for diagnostic tests (table 2). ${ }^{17}$ Statistical pooling was undertaken as appropriate if there was no systematic review. ${ }^{18}$

\section{Outcome measures}

As there is no agreed gold standard for diagnosis of HOA, established methods such as radiographic changes and expert diagnosis were used as the diagnostic reference to determine the validity of a test. Validity was evaluated by sensitivity, specificity and likelihood ratio (LR) (LR = sensitivity/(1specificity)). ${ }^{17}$ LRs above 10 or below 0.1 are considered strong evidence to respectively rule in or rule out a diagnosis in most circumstances. ${ }^{19}$ For continuous data, we used receiver operating curve (ROC). ${ }^{20}$ ROC $=1$ means $100 \%$ sensitive and specific. Test reliability was assessed using kappa statistics (dichotomous data) and intra-class correlation analysis (continuous data). Relative risk $(\mathrm{RR})$ and odds ratio (OR) were calculated for risk factors and comorbidities associated with HOA. ${ }^{15} 21$ For economic evaluations, the incremental costeffective ratio (ICER) was presented. ${ }^{17}$ Strength of recommendation (SOR) was graded using the EULAR 0-100 mm visual analogue scale (VAS). ${ }^{14}$

\section{Future research agenda}

After the propositions for diagnosis had been searched, reviewed and discussed, each participant proposed independently 10 propositions for future research. Consensus was obtained using the Delphi technique. 
Table 1 Glossary

\begin{tabular}{ll}
\hline Term & Definition \\
\hline Heberden and Bouchard nodes & $\begin{array}{l}\text { Clinically defined posterolateral firm/hard swellings. Heberden: distal IPJ; Bouchard: } \\
\text { proximal IPJ. }\end{array}$ \\
& $\begin{array}{l}\text { Nodes can occur with or without radiological and/or clinical abnormalities } \\
\text { characteristics of HOA. } \\
\text { Heberden and/or Bouchard nodes plus underlying IPJ OA, defined clinically and/or } \\
\text { radiologically. }\end{array}$ \\
Nodal OA & IPJ OA, defined clinical and/or radiographically, without nodes \\
Non-nodal OA & Subset of HOA defined radiographically by subchondral erosion, cortical destruction and \\
Erosive OA & subsequent reparative change, which may include bony ankylosis. \\
Generalised OA & HOA plus OA at other sites. \\
Thumb base OA & First CMCJ with or without STJ OA \\
Gold standard & The diagnostic reference used for a particular study \\
\hline CMCJ, carpometacarpal joint; HOA, hand OA; IPJ, interphalangeal joint; OA, osteoarthritis; STJ, scapho-trapezioid joint.
\end{tabular}

\section{RESULTS}

\section{General literature}

The literature search yielded 6101 hits. After deleting duplications, 2525 hits remained. Of them, only 108 studies met the inclusion criteria. Whist over half of them (52\%) were studies for risk factors or comorbidities, others were studies for clinical features $(22 \%)$, radiographs $(9 \%)$, clinical and radiographic features (6\%), other imaging (8\%) (eg, ultrasound, MRI, scintigraphy) and laboratory markers (3\%) (eg, erythrocyte sedimentation rate (ESR) and rheumatoid factor (RF)) (fig 1). Radiographs were the main "gold" standard used in these studies (39\%). Other "gold" standards included clinical (21\%), clinical and radiographic (23\%) and indeterminate (17\%). The majority of studies were cross-sectional (63\%), followed by case control (23\%), cohort (11\%) and systematic review (3\%).

\section{EULAR recommendations}

Of 184 propositions suggested for diagnosis, 10 were agreed after 3 anonymous Delphi rounds (table 3 ).

\section{Proposition 1}

Risk factors for HOA include female sex, increasing age over 40, menopausal status, family history, obesity, higher bone density, greater forearm muscle strength, joint laxity, prior hand injury and occupation or recreation-related usage.

\section{Strength of recommendation (95\% CI): 69 (54 to 84)}

The gender difference for $\mathrm{HOA}$ has been systematically reviewed, examining 2 incidence and 14 prevalence studies. Women have a slightly greater prevalent risk of HOA than men, with relative risks of 1.54 (95\% CI 0.83 to 2.86 ) for incidence and 1.23 (95\% CI 1.11 to 1.34 ) for prevalence respectively. ${ }^{22}$ When female gender is used as a diagnostic criterion to differentiate HOA from other types of hand arthritis the LR is not statistically significant ( $\mathrm{LR}=0.94,95 \% \mathrm{CI} 0.80$ to 1.13$){ }^{8}$

Table 2 EULAR evidence hierarchy for diagnosis based on study design $^{17}$

\begin{tabular}{ll}
\hline Hierarchy level & Description \\
\hline la & Meta-analysis of cohort studies \\
Ib & Meta-analysis of case control studies \\
Ila & Cohort studies \\
Ilb & Case control/cross sectional comparative studies \\
III & Non-comparative descriptive studies \\
IV & Expert opinion \\
\hline
\end{tabular}

It is rare for HOA to develop before the age of 40, but after this age the incidence increases dramatically, especially in women (fig 2). ${ }^{23}$ Age has been confirmed in many studies as one of the major risk factors for $\mathrm{HOA}^{23-28}$ and when a cut-off of 40 years is used it has an LR of 3.73 (95\% CI 2.69 to 5.18) (fig 3$)^{8}$

Certain occupations such as cotton picking ${ }^{29}$ increase the risk of HOA. This was confirmed by a systematic review of 11 case control and cross-sectional studies. The risk was dose-dependent, mainly targeting distal interphalangeal (DIP) joints and metacarpophalangeal (MCP) joints but showing differential joint distribution within the hand depending on the repetitive tasks involved. ${ }^{30}$

Sex hormones may influence the development of HOA in women. It was signalled by the gender difference dependent on age, ie, women have lower incidence of HOA before the age of 40 but higher incidence after this age than men. ${ }^{23}{ }^{31}$ The reduction in oestrogen due to the menopause is therefore suggested. However, this is not supported by the evidence observed from the hormone replacement therapy (HRT) studies, where the use of HRT was not associated with the reduced risk of $\mathrm{HOA}^{32-35}$ As these studies were observational studies, they may be confounded by other factors such as the increased bone density (a potential risk factor for HOA) due to HRT. ${ }^{36-40}$ Randomised controlled trials in this regard are still required.

Other well established risk factors for HOA include positive family history, ${ }^{81-44}$ obesity, ${ }^{864045-49}$ and joint injury. ${ }^{40}$ High forearm extensor muscle strength has also been suggested as a risk factor, presumably by increasing damaging mechanical forces in the hand ${ }^{50}$ (table 4).

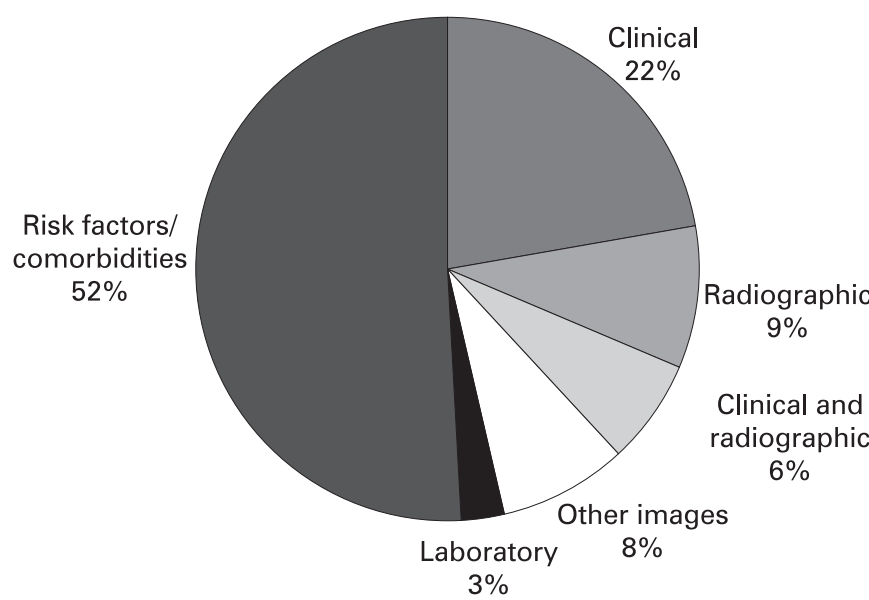

Figure 1 Diagnostic tests or elements examined in hand osteoarthritis. 


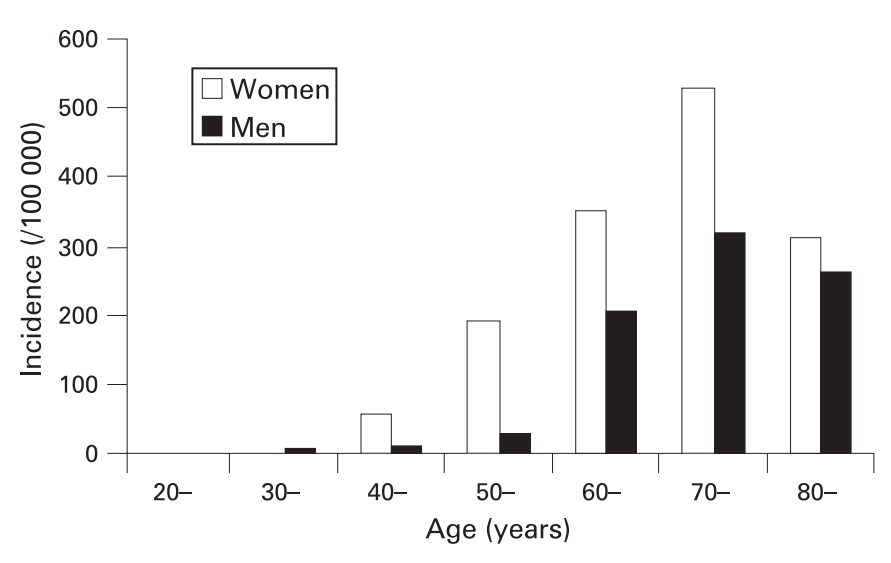

Figure 2 Incidence of hand osteoarthritis by age and sex 1991-1992.

In summary, major risk factors for $\mathrm{HOA}$ include age over 40 years (evidence level IIa), female gender (evidence level Ib), positive family history (evidence level $\mathrm{Ib}$ ), occupational usage (evidence level $\mathrm{Ib}$ ), obesity (evidence level IIa) and finger joint injury (evidence level IIb). However, the diagnostic usefulness of these risk factors, singly or in combination, requires further study.

\section{Proposition 2}

Typical symptoms of $\mathrm{HOA}$ are pain on usage and only mild morning or inactivity stiffness affecting just one or a few joints at any one time; symptoms are often intermittent and target characteristic sites (DIPJs, PIPJs, thumb base, index and MCPJs).
With such typical features, a confident clinical diagnosis can be made in adults aged over 40.

Strength of recommendation (95\% CI): 85 (77 to 92)

Pain on usage has limited value for the diagnosis of $\mathrm{HOA}$ Whilst this feature has excellent reliability (kappa 0.85 to 1.00 ) and specificity (0.94 to 0.99 ), the sensitivity is extremely low (0.01 to 0.10 ) and the LR ranges from 0.50 to $5.50 .{ }^{11}$ However, limited duration of localised morning or inactivity stiffness is more specific to $\mathrm{HOA}$ than inflammatory arthritis. ${ }^{51}$ By contrast, the presence of uncharacterised hand pain (unspecified in terms of location, relationship to usage or rest) is not specific to $\mathrm{HOA}^{7}$ Pain in $\mathrm{HOA}$ is variable in severity and often varies with time

HOA mainly targets DIP, PIP and thumb base joints. $^{8242527285253}$ The prevalence of symptomatic HOA is highest with DIP, followed by thumb base, PIP and MCP joints. ${ }^{27} 285254$ The distribution of HOA clusters by row and by ray. ${ }^{52}{ }^{55}$ The presence of $\mathrm{OA}$ at one finger joint is associated with $\mathrm{OA}$ at other finger joints in the same row (OR 6.4, 95\% CI 4.3 to 9.4 in men and $5.2,95 \%$ CI 4.5 to 6.0 in women), and the same ray $(\mathrm{OR}=5.3,95 \%$ CI 2.9 to 10.0 in men and $3.3,95 \%$ CI 2.6 to 4.2 in women) of the same hand. ${ }^{52} \mathrm{HOA}$ also shows symmetry between hands, ${ }^{52-57}$ more so for radiographic joint space narrowing (JSN) than for osteophyte. ${ }^{57}$ The presence of OA at a particular finger joint strongly associates with $\mathrm{OA}$ in the same joint of the opposite hand $(\mathrm{OR}=14.0,95 \%$ CI 7.1 to 27.8 in men and $29.8,95 \%$ CI 19.2 to 46.3 in women). ${ }^{52}$

In summary, pain on usage is not a specific clinical marker for HOA (evidence level IIb). However, HOA strongly targets DIP, PIP and thumb base joints and the shorter duration of morning

Table 3 Propositions and strength of recommendation (SOR) - order according to topic (risk factors, clinical, subsets, differential diagnosis, images and laboratory tests)

\begin{tabular}{|c|c|c|c|}
\hline No. & Proposition & LoE & SOR $(95 \% \mathrm{CI})$ \\
\hline 1 & $\begin{array}{l}\text { Risk factors for HOA include female sex, increasing age over } 40 \text {, menopausal status, family history, obesity, higher } \\
\text { bone density, greater forearm muscle strength, joint laxity, prior hand injury and occupation or recreation-related } \\
\text { usage. }\end{array}$ & $\mathrm{lb}-\mathrm{Ilb}$ & 69 (54 to 84$)$ \\
\hline 2 & $\begin{array}{l}\text { Typical symptoms of HOA are pain on usage and only mild morning or inactivity stiffness affecting just one or } \\
\text { a few joints at any one time; symptoms are often intermittent and target characteristic sites (DIPJs, PIPJs, } \\
\text { thumb base, index and middle MCPJs). With such typical features, a confident clinical diagnosis can be made } \\
\text { in adults aged over } 40 .\end{array}$ & llb & 85 (77 to 92$)$ \\
\hline 3 & $\begin{array}{l}\text { Clinical hallmarks of HOA are Heberden and Bouchard nodes and/or bony enlargement with or without deformity } \\
\text { (eg, lateral deviation of IPJs, subluxation and adduction of thumb base) affecting characteristic target joints } \\
\text { (DIPJs, PIPJs, thumb base and index and middle MCPJs). }\end{array}$ & Ib-IV & 80 (69 to 90$)$ \\
\hline 4 & $\begin{array}{l}\text { Functional impairment in hand } \mathrm{OA} \text { may be as severe as in rheumatoid arthritis. Function should be carefully } \\
\text { assessed and monitored using validated outcome measures. }\end{array}$ & $\mathrm{llb}$ & 57 (42 to 73 ) \\
\hline 5 & $\begin{array}{l}\text { Patients with polyarticular } \mathrm{HOA} \text { are at increased risk of knee } \mathrm{OA} \text {, hip } \mathrm{OA} \text { and } \mathrm{OA} \text { at other common target sites } \\
\text { (generalised } \mathrm{OA} \text { ) and should be assessed and examined accordingly. }\end{array}$ & Ila-Ilb & 77 (62 to 92 ) \\
\hline 6 & $\begin{array}{l}\text { Recognised subsets with different risk factors, associations and outcomes (requiring different assessment and } \\
\text { management) include IPJ OA (with or without nodes), thumb base OA and erosive OA. Each may be symptomatic } \\
\text { or asymptomatic. }\end{array}$ & Ila-Ilb & 68 (56 to 79$)$ \\
\hline 7 & $\begin{array}{l}\text { Erosive hand OA targets IPJs and shows radiographic subchondral erosion, which may progress to marked bone } \\
\text { and cartilage attrition, instability and bony ankylosis. Typically it has an abrupt onset, marked pain and functional } \\
\text { impairment, inflammatory symptoms and signs (stiffness, soft tissue swelling, erythaema, paraesthesiae), mildly } \\
\text { elevated CRP levels, and a worse outcome than non-erosive IPJ OA. }\end{array}$ & Ila-Ilb & 87 (81 to 93) \\
\hline 8 & $\begin{array}{l}\text { The differential diagnosis for HOA is wide. The commonest conditions to consider are psoriatic arthritis (which may } \\
\text { target DIPJs or affect just one ray), rheumatoid arthritis (mainly targeting MCPJs, PIPJs, wrists), gout (which may } \\
\text { superimpose on pre-existing HOA), and haemochromatosis (mainly targeting MCPJs, wrists). }\end{array}$ & $\mathrm{lb}-\mathrm{Ilb}$ & 81 (73 to 89$)$ \\
\hline 9 & $\begin{array}{l}\text { Plain radiographs provide the gold standard for morphological assessment of HOA. A posteroanterior radiograph of } \\
\text { both hands on a single film/field of view is adequate for diagnosis. Classical features are joint space narrowing, } \\
\text { osteophyte, subchondral bone sclerosis and subchondral cyst, and subchondral erosion occurs in erosive hand OA. } \\
\text { Further imaging modalities are seldom indicated for diagnosis. }\end{array}$ & $\mathrm{lb}-\mathrm{Ilb}$ & 87 (81 to 93) \\
\hline 10 & $\begin{array}{l}\text { Blood tests are not required for diagnosis of HOA but may be required to exclude coexistent disease. In a patient } \\
\text { with HOA who has marked inflammatory symptoms and/or signs, especially involving atypical sites, blood tests } \\
\text { should be undertaken to screen for additional inflammatory arthritides. }\end{array}$ & $\mathrm{lb}-\mathrm{Ilb}$ & 78 (63 to 92$)$ \\
\hline
\end{tabular}

CRP, C-reactive protein; DIPJ, distal IPJ; IPJ, interphalangeal joint; HOA, hand osteoarthritis; LoE, level of evidence (see table 2 for further details), presented in range upon components assessed; MCPJ, metacarpophalangeal joints; PIPJ, proximal IPJ; SOR, strength of recommendation on visual analogue scale $(0-100$ mm, $0=$ not recommended at all, $100=$ fully recommended). 
Figure 3 Likelihood ratio (LR) and 95\% $\mathrm{Cl}$ of different diagnostic makers or $\mathrm{LR}=10$ ). features (useful ruled in cut-off level

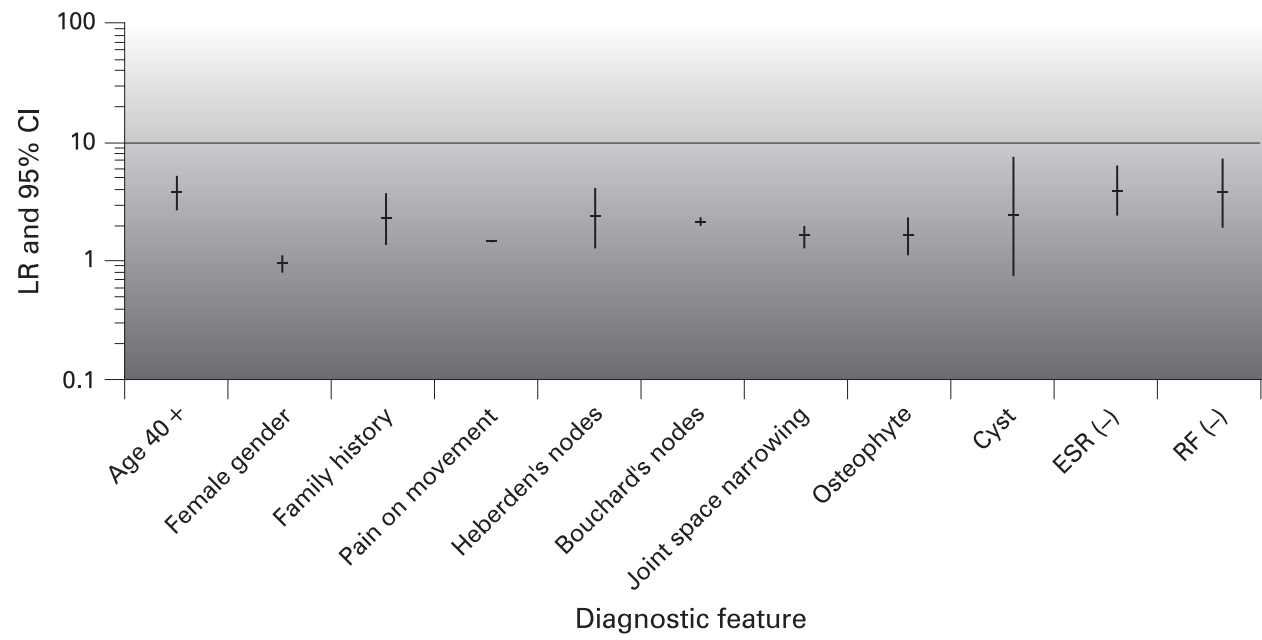

or inactivity stiffness plus clustering pattern and symmetric distribution may be useful to distinguish HOA from other forms of hand arthritis (evidence level IIb).

\section{Proposition 3}

Clinical hallmarks of HOA are Heberden and Bouchard nodes and/or bony enlargement with or without deformity (eg, lateral deviation of IPJs, subluxation and adduction of thumb base) affecting characteristic target joints (DIPJs, PIPJs, thumb base and index and middle MCPJs).

\section{Strength of recommendation (95\% CI): 80 (69 to 90 )}

Heberden nodes (HN) and Bouchard nodes (BN) associate with underlying structural changes of $\mathrm{HOA}$, especially osteophyte $(\mathrm{OR}=5.15,95 \%$ CI 4.37 to 6.08$) ..^{58-60}$ However, their sensitivity and specificity for $\mathrm{HOA}$ vary widely from 0.3 to 0.9 depending on the cut-off grade, gold standard and control subjects. This in part may reflect the common time lag between development of nodes and appearance of structural $x$ ray change. Subsequently $\mathrm{HN}$ or BN have limited value as a single diagnostic marker with an LR ranging from 0.50 to 5.50 and a median of 1.46 (fig 3). However, nodes become more useful when taken in combination with other HOA features (fig 4). For example, the probability of a subject with $\mathrm{HOA}$ is $20 \%$ when $\mathrm{HN}$ alone are considered, but this increases to $88 \%$ when the subject is over 40 years old, has a family history of $\mathrm{HN}$ and has joint space narrowing in any finger joint.
In brief, $\mathrm{HN}$ and $\mathrm{BN}$ are important clinical markers for diagnosis of HOA, especially when used in combination with other features of HOA (evidence level Ib). Research evidence for the diagnostic values of other clinically-derived features and their distribution is lacking (evidence level IV).

\section{Proposition 4}

Functional impairment in hand OA may be as severe as in rheumatoid arthritis. Function should be carefully assessed and monitored using validated outcome measures.

Strength of recommendation (95\% CI): 57 (42 to 73)

A number of studies have examined the functional impact of HOA. ${ }^{6}{ }^{281-66}$ Pain $^{64}$ and radiographic changes ${ }^{65}$ associate with impaired hand function in the setting of HOA. Functional impairment due to $\mathrm{HOA}$ may be similar in severity to that resulting from rheumatoid arthritis ${ }^{67}$ (evidence level IIb). Indeed, for many patients with HOA functional difficulty is their main presenting complaint. However, in one study the eventual functional outcome of fully established HOA (symptom onset $\geqslant 10$ years before) was found to be relatively optimistic for nodal OA but not for erosive OA. ${ }^{66}$

A number of validated instruments are available to assess hand function. These include the Health Assessment Questionnaire (HAQ), ${ }^{68}$ the Arthritis Hand Function Test (AHFT), ${ }^{69}$ the Arthritis Impact Measurement Scale 2 (AIMS2), ${ }^{70}$ the Cochin scale, ${ }^{71}$ the Score for Assessment and

Table 4 Risk factors and hand osteoarthritis (OA)

\begin{tabular}{|c|c|c|c|c|}
\hline Risk factor & LoE* $^{*}$ & Sample size & RR/OR (95\% Cl) & Reference \\
\hline Female gender & $\mathrm{lb}$ & 14 studies & $1.23(1.11$ to 1.34$)$ & Rovetta et $a l^{22}$ \\
\hline Age, $>40$ & Ilb & 194 & $3.68(2.66$ to 5.09$)$ & Altman et $a l^{\beta}$ \\
\hline Family history, 1 st degree etc & $\mathrm{lb}$ & 3 studies $(n=4183)$ & 2.57 (1.86 to 3.55$)$ & $\begin{array}{l}\text { Altman et al }{ }^{8} \text { Marcelli et } a l_{,}{ }^{41} \\
\text { Schneider et } a l^{42}\end{array}$ \\
\hline \multicolumn{5}{|l|}{ Obesity: } \\
\hline Relative weight index, per $20 \%$ increase & Ila & 1276 & 1.69 (1.27 to 2.18$)$ & Spector and MacGregor ${ }^{46}$ \\
\hline $\mathrm{BMI},>29$ vs $\leqslant 24$ & Illb & 78 & $8.3(1.2$ to 56.5$)$ & Carman et $a l^{49}$ \\
\hline $\mathrm{BMI}, \mathrm{kg} / \mathrm{m}^{2}$ & $\mathrm{Ilb}$ & 82 pairs & $1.30(1.06$ to 1.59$)$ & Zhang and Doherty ${ }^{47}$ \\
\hline BMI, kg/m² & $\mathrm{llb}$ & 573 women & $1.03(0.96$ to 1.11$)$ & Hochberg et $a l^{40}$ \\
\hline \multirow[t]{2}{*}{$\mathrm{BMD}, \mathrm{dg} / \mathrm{cm}^{2}$} & $\mathrm{llb}$ & 573 women & $1.11(0.61$ to 2.02$) \mathrm{kl} \geqslant 2$ & Hochberg et $a l^{40}$ \\
\hline & & & $1.61(1.27$ to 2.07$) \mathrm{kl}=4$ & \\
\hline Grip strength, third tertile & Ila & 756 & $2.8(1.2$ to 6.7$)$ & Cicutinni et $a l^{50}$ \\
\hline History of hand injury & $\mathrm{Ilb}$ & 573 women & $3.64(1.34$ to 9.88$)$ & Hochberg et $a l^{40}$ \\
\hline
\end{tabular}

\footnotetext{
* See table 2 for further description.
}

$B M D$, bone mineral density' BMI, body mass index; $L O E$, level of evidence; $O R$, odds ratio; $R R$, relative risk. 
Figure 4 Diagnostic ladder of hand osteoarthritis (OA) (source population prevalence $10 \%$ ).

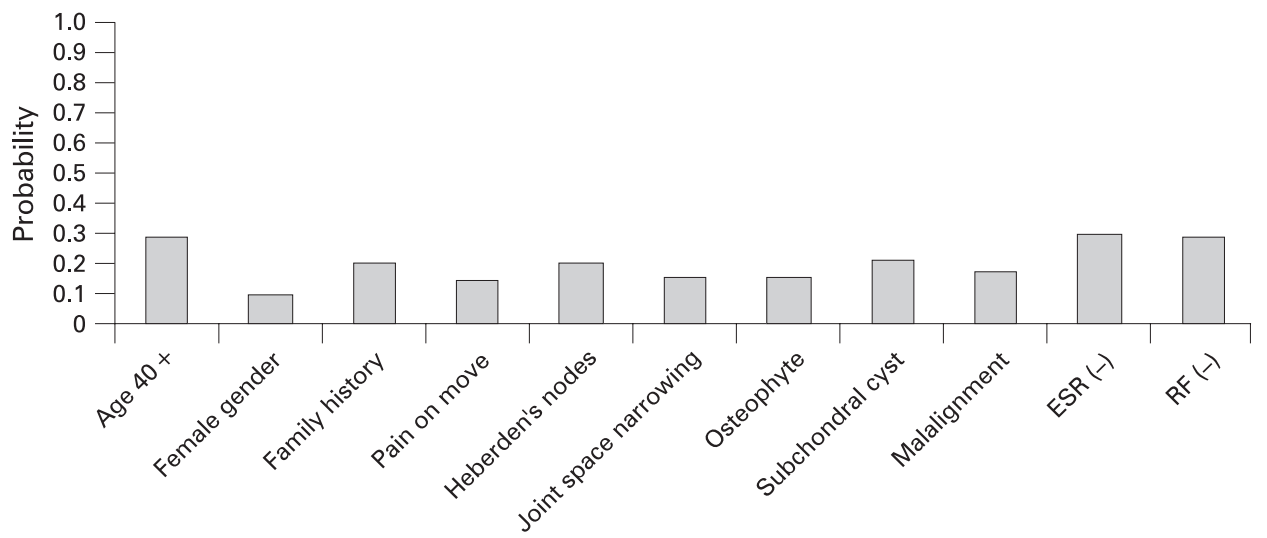

Single test

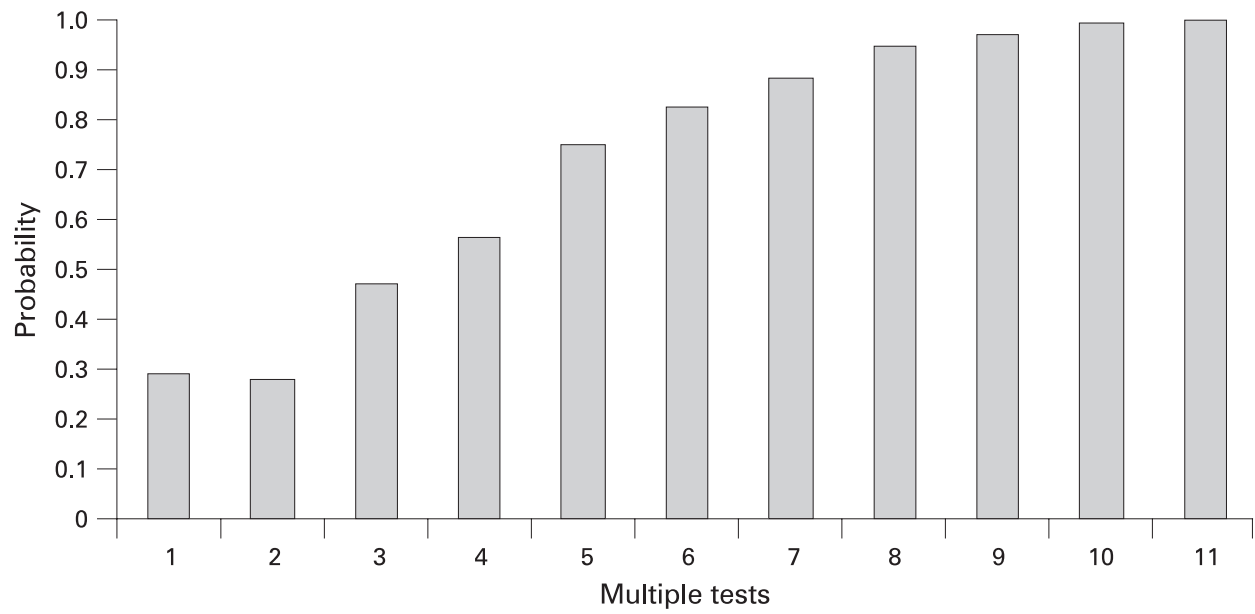

quantification of Chronic Rheumatic Affections of the Hands (SACRAH) ${ }^{67}{ }^{72}$ the Functional Index for Osteoarthritis of the Hand (FIHOA) ${ }^{61}$ and the Australian/Canadian Osteoarthritis Hand Index (AUSCAN). ${ }^{73}$ A systematic review of these instruments has been undertaken. ${ }^{74}$ There is no universal instrument and the selection from these options is guided mainly by the clinical question (evidence level $\mathrm{Ib}$ ).

\section{Propostion 5}

Patients with polyarticular HOA are at increased risk of knee $\mathrm{OA}$, hip $\mathrm{OA}$ and $\mathrm{OA}$ at other common target sites (generalised $\mathrm{OA})$ and should be assessed and examined accordingly.

\section{Strength of recommendation $(95 \% \mathrm{CI}): 77$ (62 to 92)}

HOA may not only affect multiple joints within the hand, it also can occur as a component of "generalised" OA. Patients with $\mathrm{HOA}$ have increased risk of knee $\mathrm{OA}(\mathrm{OR}=3.0,95 \% \mathrm{CI}$ 1.2 to 7.5$)^{75}$ and hip $\mathrm{OA}(\mathrm{OR}=3.25,95 \% \text { CI } 2.19 \text { to } 4.84)^{76}$ (evidence level IIb). A recent population-based cohort study that followed 1235 subjects without hip and knee OA at baseline for over 6 years showed that the risk of developing knee OA or hip OA was two times greater $(\mathrm{OR}=2.1,95 \%$ CI 1.3 to 3.1$)$ in those with HOA than in those without $\mathrm{HOA}$ at baseline ${ }^{5}$ (evidence level IIa).

OA of recognised target joints (DIP, PIP, carpometacarpal (CMC), knee, hip) correlates with each other which often appear in a cluster of three or more involved groups. ${ }^{25}$ The strongest associations occur for DIP and PIP, followed by PIP and CMC, CMC and knee, PIP and knee, knee and hip and DIP and knee (table 5). These data support the concept of "generalised OA" in which some individuals are at increased risk of multiple joint involvement by $\mathrm{OA}$. Classification criteria for generalised versus focal OA have been proposed. ${ }^{4}$ There is clear justification to include assessment of other target joints for $\mathrm{OA}$ for the purpose of diagnosis and treatment planning of HOA.

\section{Proposition 6}

Recognised subsets with different risk factors, associations and outcomes (requiring different assessment and management) include IPJ OA (with or without nodes), thumb base OA and erosive OA. Each may be symptomatic or asymptomatic.

\section{Strength of recommendation (95\% CI): 68 (56 to 79 )}

A number of studies have identified differences between erosive and non-erosive OA (see proposition 7) (evidence level IIa-IIb).

Table 5 Association of osteoarthritis between joints ${ }^{25}$

\begin{tabular}{llc}
\hline Index joints & Other joints & OR $(\mathbf{9 5 \%}$ CI) \\
\hline DIP & PIP & $31.7(13.8$ to 72.5$)$ \\
PIP & CMC & $4.8(2.7$ to 8.4$)$ \\
CMC & Knee & $2.4(1.5$ to 4.4$)$ \\
PIP & Knee & $2.4(1.3$ to 4.4$)$ \\
Knee & Hip & $2.1(1.2$ to 3.4$)$ \\
DIP & Knee & $1.8(1.1$ to 3.1$)$
\end{tabular}

$\mathrm{CMC}$, carpometacarpal; DIP, distal interphalangeal; PIP, proximal interphalangeal; $\mathrm{OR}$, odds ratio. 
Although HOA clusters by joints, population-based crosssectional studies have confirmed that isolated thumb base $O A$ is a common occurrence. ${ }^{77}$ Apart from the location, thumb base $\mathrm{OA}$ may associate with different risk factors from IPJ OA, although both may share a similar genetic risk. ${ }^{41}$ For example, hypermobility has been reported as a risk factor for thumb base $\mathrm{OA}^{78}$ but a negative risk ("protective") factor for IPJ OA. ${ }^{78} 79$ Studies on functional impairment have not confirmed any clear difference between thumb base $\mathrm{OA}$ and IPJ $\mathrm{OA}^{80}$ (evidence level IIb), however the long-term functional outcome for erosive $\mathrm{OA}$ appears worse than for nodal OA. ${ }^{66}$ Further research is required to define how clearly such subsets are delineated.

\section{Proposition 7}

Erosive hand OA targets IPJs and shows radiographic subchondral erosion, which may progress to marked bone and cartilage attrition, instability and bony ankylosis. Typically it has an abrupt onset, marked pain and functional impairment, inflammatory symptoms and signs (stiffness, soft tissue swelling, erythaema, paraesthesiae), mildly elevated C-reactive protein (CRP) levels and a worse outcome than non-erosive IPJ OA.

\section{Strength of recommendation $(95 \% \mathrm{CI}): 87$ (81 to 93 )}

An age and gender matched case control study has compared radiographic features of erosive $\mathrm{OA}(\mathrm{n}=33)$ and nodal $\mathrm{OA}$ $(\mathrm{n}=33)$ using summated scores for individual OA features (JSN, osteophyte, subchondral sclerosis, subchondral cysts) at different joint sites. Erosive OA had significantly higher scores than nodal OA at DIP, PIP and thumb IP joints, but not at MCP and CMC joints, supporting the selective targeting of IP joints by erosive OA. ${ }^{81}$ This observation is supported by two cohort studies. $^{82} 83$ In two case control studies subchondral erosion, bony collapse and ankylosis of IP joints appeared specific to erosive $\mathrm{OA} .{ }^{81}{ }^{84}$ In one case control study comparing hand function in patients with erosive $(n=10)$, nodal OA $(n=57)$ and normal subjects $(n=52)$, hand function was worse in the patients with erosive OA. ${ }^{66}$

One case control study has examined differences in capillaroscopic abnormalities between erosive $\mathrm{OA}$ and nodal OA. Although some statistically significant differences were found for frequency of microhaemorrhages, tortuous capillary loops and shortened loops, they did not prove very discriminatory with LRs of 2.19 (95\% CI 0.62 to 7.78$), 1.21$ (1.85 to 1.74) and 3.29 (1.34 to 8.07 ) respectively. ${ }^{85}$

Serum CRP levels have been measured in a case control study examining 67 patients with erosive $\mathrm{OA}$ and 31 patients with non-erosive OA. CRP levels were higher in the erosive OA group and the correlations between CRP level, radiographic severity scores and number of joints involved supported CRP as an indicator of disease activity. ${ }^{86}$ No differences in serum levels of type II cartilage biomarkers (Col2-3/4C, C2C and CS846 epitope) were demonstrated between 30 patients with erosive $\mathrm{OA}$ and 29 patients with non-erosive OA. ${ }^{87}$

Ultrasound has been investigated as a means to differentiate erosive $\mathrm{OA}$, non-erosive $\mathrm{OA}$ and normal joints. One case control study $(n=60)$ including 20 subjects per group found ultrasound to differentiate erosive OA from normal (ROC 0.75; ROC 1 means $100 \%$ sensitive and specific) and non-erosive OA from normal (ROC 0.73), but not erosive OA from non-erosive $\mathrm{OA}$ (ROC: not reported). ${ }^{88}$

In summary, erosive $\mathrm{OA}$ appears to be a specific subgroup of HOA with worse clinical and structural outcomes. It targets mainly the IP joints with structural changes that are often severe (subchondral erosion, ankylosis) and inflammation (elevated CRP) (evidence level IIa-IIb).

\section{Proposition 8}

The differential diagnosis for HOA is wide. The commonest conditions to consider are psoriatic arthritis (which may target DIPJs or affect just one ray), rheumatoid arthritis (mainly targeting MCPJs, PIPJs, wrists), gout (which may superimpose on pre-existing $\mathrm{HOA}$ ) and haemochromatosis (mainly targeting MCPJs, wrists)

Strength of recommendation (95\% CI): 81 (73 to 89 )

The differential diagnosis between HOA and other arthropathy may be based on clinical manifestations (eg, age, gender, onset and progression of symptoms, degree of stiffness, joints involved (fig 5), presence of $\mathrm{HN} / \mathrm{BN}$, examination findings of synovitis and/or damage), radiographic changes (fig 6) and laboratory tests. However, as for diagnosis, a single criterion on its own has limited sensitivity and specificity (figs 3 and 4). For example, although DIP joints are mainly targeted by OA they can also be involved in rheumatoid arthritis (RA), ${ }^{9}$ inflammatory symptoms and signs and elevation of CRP may occur with erosive $\mathrm{OA}$ and $\mathrm{RA}$, radiographic changes of $\mathrm{HOA}$ and calcium pyrophosphate dehydrate deposition disease (CPPD) associated arthritis are extremely similar, ${ }^{89}$ and $\mathrm{HOA}$ may coexist with CPPD, ${ }^{90} 91$ gout or RA.

A composite of multiple features is more useful, such as age, female gender, joint distribution, bone swelling (not soft tissue) and radiographic changes. Laboratory tests, although nonspecific, may assist in this, for example strongly positive RF is supportive of RA and elevated urate may support gout. Some individual features do have high specificity (eg non-proliferative marginal erosion for RA, urate crystals for gout).

In brief, differential diagnosis of $\mathrm{HOA}$ and other types of hand arthritis depends largely on the use of a composite of features (evidence level $\mathrm{Ib}$ ). Certain features for individual diseases may be useful for specific cases (evidence level IIb).

\section{Proposition 9}

Plain radiographs provide the gold standard for morphological assessment of HOA. A posteroanterior radiograph of both hands on a single film/field of view is adequate for diagnosis. Classical features are joint space narrowing, osteophyte, subchondral bone sclerosis and subchondral cyst; subchondral erosion occurs in erosive hand OA. Further imaging modalities are seldom indicated for diagnosis.

\section{Strength of recommendation (95\% CI): 87 (81 to 93)}

Structural changes on plain radiographs have been used by the majority of studies as the "gold standard" for the assessment of a diagnostic test. ${ }^{92-95}$ The validity of radiographic change itself has been examined in two case control studies in which the clinical diagnosis was used as the "gold standard".89 Classical radiographic features such as JSN and osteophyte are sensitive (sensitivity $0.75-1.0$ ) but not specific (specificity 0.18-0.71), resulting in small LRs (pooled LR1.60, 95\% CI 1.29 to 1.99 for JSN and $1.61,95 \%$ CI 1.12 to 2.33 for osteophyte) (fig 3). Thus, a single feature (eg, JSN or osteophyte) is less valuable for the diagnosis than a composite of two or more features (fig 4).

The intra-reader reliability (kappa) of radiographic features for HOA ranges from 0.38 to 1.0 (kappa $0.56-1.00$ for PIP joints, $0.38-0.87$ for DIP joints and $0.58-0.69$ for CMC-1 joints) and the inter-reader reliability (kappa) ranges from $0.52-0.92 . .^{96}$ The latter may be improved by reader's experience (0.92-1.00). ${ }^{97} 98$ Reliability also varies according to the scale used, eg, the Verbruggen and Kellgren and Lawrence scale may have better reproducibility than global and Kallman scales. ${ }^{98}$ 


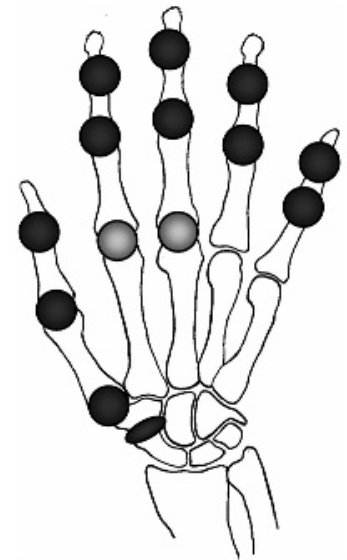

Hand OA

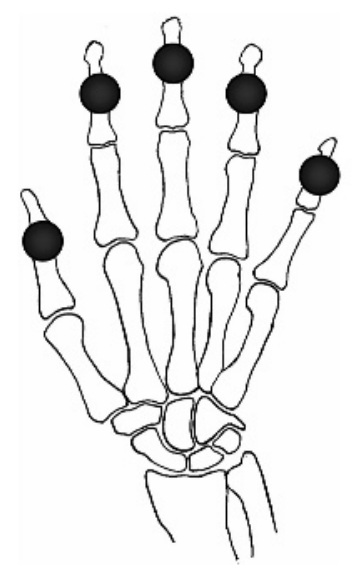

Psoriatic arthritis DIPJ pattern

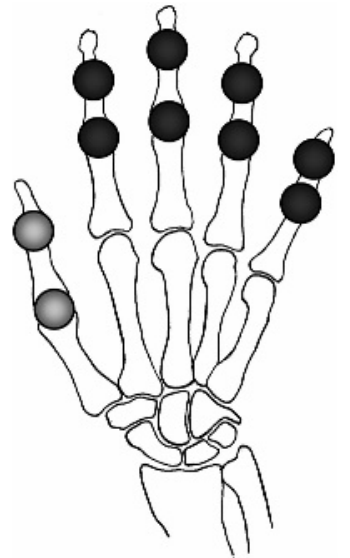

Erosive OA

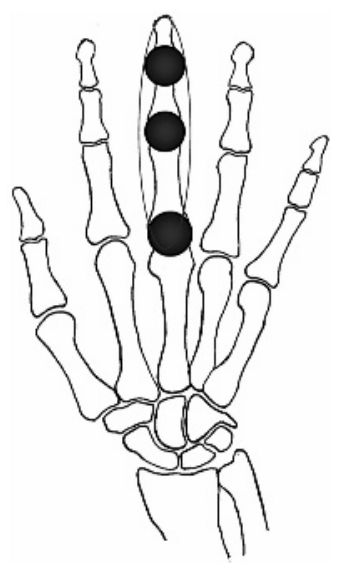

Psoriatic arthritis dactylitis pattern (arthritis, osteitis, adjacent peri-articular inflammation)

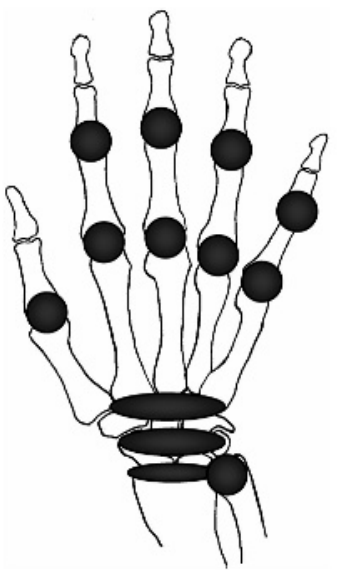

Rheumatoid arthritis

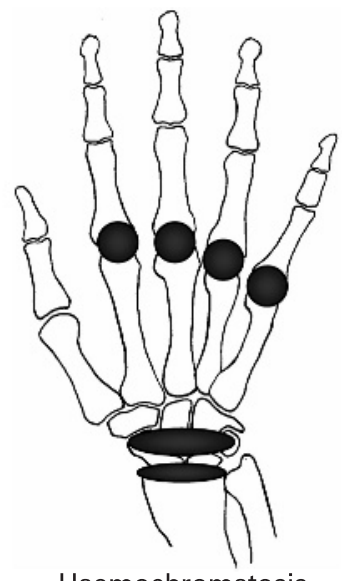

Haemochromatosis
Figure 5 Target sites of involvement with hand osteoarthritis (HOA), erosive $0 A$, psoriatic arthritis, rheumatoid arthritis and haemochromatosis.

Other images such as scintigraphy and MRI have been investigated, especially for the early diagnosis of HOA. ${ }^{92} 9499$ However, their values have yet to be confirmed.

In summary, the plain radiograph is the validated principle imaging technique to examine morphological changes of HOA (evidence level IIb). Diagnosis based on a single radiographic feature (eg, JSN or osteophyte) has limited value, whereas presence of multiple features, especially a composite of clinical and radiographic changes, dramatically improves diagnostic certainty (evidence level $\mathrm{Ib}$ ). Other imaging techniques are relatively understudied and their clinical applications have yet to be determined.

\section{Proposition 10}

Blood tests are not required for diagnosis of HOA but may be required to exclude coexistent disease. In a patient with $\mathrm{HOA}$ who has marked inflammatory symptoms and/or signs, especially involving atypical sites, blood tests should be undertaken to screen for additional inflammatory arthritides.

Strength of recommendation $(95 \% \mathrm{CI}): 78$ (63 to 92 )

Unlike RA or other forms of inflammatory arthritis, inflammatory markers are not usually elevated in HOA. It is well documented that ESR, RF (evidence level $\mathrm{Ib}$ ) and CRP (evidence level IIb) are usually normal/negative or only mildly elevated/ positive in non-erosive OA (fig 3). ${ }^{89518586}$ Therefore more pronounced abnormalities should lead to a search for an alternative explanation. However, as discussed, a single blood test may be unable to differentiate between erosive OA and RA, or confirm the presence of coexisting inflammatory arthropathy. It is necessary to consider other clinical and investigational features that are more characteristic and/or specific for each condition (eg, proliferative or non-proliferative marginal erosions in psoriatic and rheumatoid arthritis respectively, elevated serum uric acid and urate crystal identification on aspiration of a joint or tophus in gout).

\section{Future research agenda}

After three Delphi rounds, nine propositions were developed (table 6).

\section{DISCUSSION}

To our knowledge these are the first evidence-based recommendation for diagnosis of $\mathrm{HOA}$. To date, the main reference cited for diagnosis of $\mathrm{HOA}$ has been the American College of Rheumatology (ACR) criteria for classification of HOA. ${ }^{8}$ However, the current recommendations differ from the ACR criteria in several important ways. Firstly, the primary purpose of these recommendations is to provide guidance to assist clinicians to diagnose $\mathrm{HOA}$, not to classify HOA for research or clinical trial purposes. The emphasis is on possible subsets and the differential diagnosis to be considered rather than on algorithms for classification of a single entity. Secondly, these are evidence-based recommendations in which research evidence has been summarised systematically from multiple studies undertaken in different countries. Therefore they have more generalisability than recommendations based on a single study population. Thirdly, clinical expertise from many countries across Europe has been incorporated within the recommendations, and importantly, the expertise has been synthesised systematically using a Delphi exercise. Therefore, the recommendations have less parochial and personal bias. ${ }^{100}$ Finally, the strength of recommendation and confidence interval has been provided for each proposition, based on research evidence and clinical expertise. This importantly reflects the magnitude of support for each statement and the confidence (variability of opinion) from the Task Force. ${ }^{100}$ This information helps clinicians to gauge which statements have good general agreement and which are more open to personal interpretation.

The topics of the 10 generated propositions are wide ranging and include risk factors for $\mathrm{HOA}$, clinical manifestations, subsets, differential diagnosis, imaging and laboratory tests. 
Figure 6 Contrasting radiographic features at interphalangeal joints (IPJs) of (A) osteoarthritis (OA): focal narrowing, marginal osteophyte, sclerosis, osteochondral bodies; (B) erosive $0 A$ : subchondral erosion; (C) psoriasis: proliferative marginal erosion, retained or increased bone density; and (D) rheumatoid arthritis: non-proliferative marginal erosion, osteopoenia.

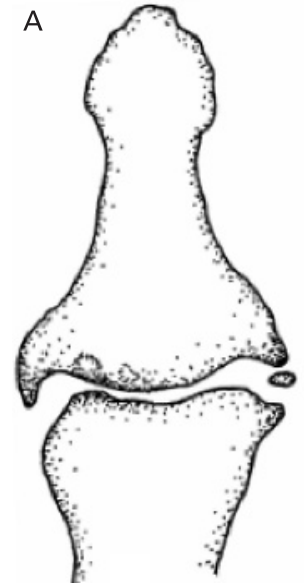

The sensitivity and specificity for each recommended marker or test has been examined and the value of each has been presented as a likelihood ratio to allow estimation of the likelihood of $\mathrm{HOA}$ given a positive test result. A diagnostic ladder has also been provided to show the probability of diagnosis of $\mathrm{HOA}$ when multiple features are considered. Clinicians may estimate the probability of $\mathrm{HOA}$ for any composite of the features that a patient may present on the knowledge of the likelihood ratio for each feature (fig 3). The Baye formula or Fagan nomogram may be used to estimate the probability. ${ }^{17}$ Overall we found that the diagnosis of $\mathrm{HOA}$ cannot be determined with confidence using a single feature and that a composite of several features is required to diagnose $\mathrm{HOA}$.

There are limitations to these recommendations. Firstly, although the evidence-based method is an accepted strategy to increase the power and generalisability of research evidence, it is still open to bias since the pooled studies may carry different confounding factors. Secondly, we only focused on key issues relating to diagnosis of $\mathrm{HOA}$ and did not attempt a comprehensive review. Thirdly, generation of the recommendations was driven from a clinical perspective and the relevant research was examined later. Therefore we may have omitted important emerging research information. Such bias, however, should have been minimised by the general literature search and discussion undertaken prior to the Delphi exercise. Finally, the Delphi consensus approach has its own limitations. Although it is systematic it has restricted flexibility and as a result some propositions may overlap or appear repetitive or illogical. Therefore we
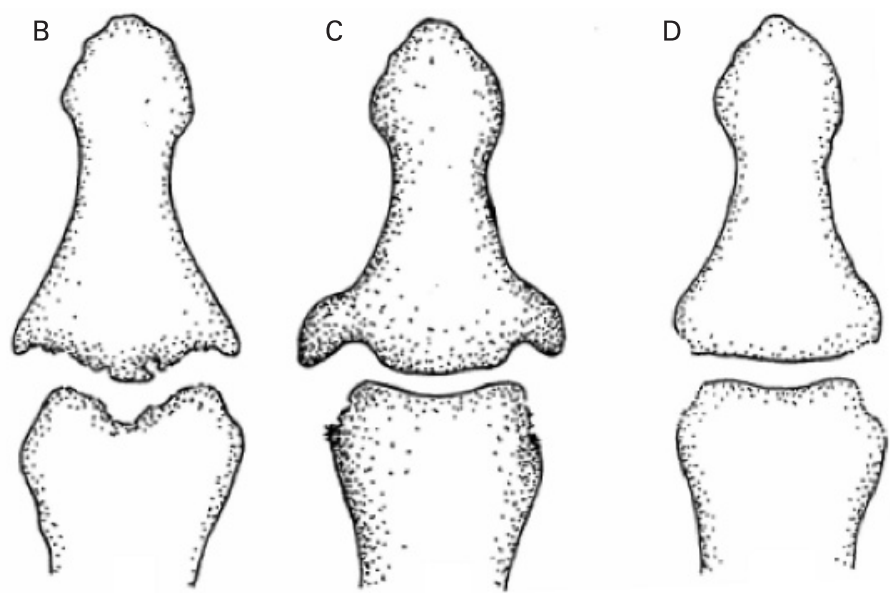

discussed the final list of the Delphi results at our last meeting to agree on necessary changes to improve clarity. During this, however, we did not delete or introduce content but did alter some phrasing and ordering of content.

In conclusion, 10 key recommendations for diagnosis of $\mathrm{HOA}$ have been generated and the level of research evidence and strength of recommendation have been provided for each. We hope these recommendations will stimulate debate and increase interest in HOA and thereby lead to improved diagnosis and assessment of people with this prevalent condition.

Author affiliations: ${ }^{1}$ Academic Rheumatology, University of Nottingham, Nottingham, UK; ${ }^{2}$ 2nd Department of Medicine, Lower Austrian Centre for Rheumatology, Stockerau, Austria; ${ }^{3}$ State Institute of Rheumatology, Russian Academic Medical School, Moscow, Russian Federation; ${ }^{4}$ MRC Epidemiology Resource Centre, Southampton General Hospital, Southampton, UK; ${ }^{5}$ Rheumatology and Clinical Immunology Department, University Medical Center Utrecht, Utrecht, The Netherlands; ${ }^{6}$ Hacettepe University, Faculty of Medicine, Department of Physical Medicine and Rehabilitation, Ankara, Turkey; ${ }^{7}$ Primary Care Musculoskeletal Research Centre, Keele University, Keele, UK; ${ }^{8}$ Clinic Im Park Hirslanden Group, Centre for Rheumatology and Bone Disease, Zurich, Switzerland; ${ }^{9}$ (retired), Athens, Greece;

${ }^{10}$ Department of Rheumatology, Leiden University Medical Centre, Leiden, The Netherlands; ${ }^{11}$ Department of Orthopaedics, Clinical Sciences Lund, Lund University, Lund, Sweden; ${ }^{12}$ Rheumatology Department, Hospital Saint-Antoine, Paris, France;

${ }^{13}$ Servicio de Reumatologia, Hospital Universitario La Paz, Madrid, Spain; ${ }^{14}$ Institute of Rheumatology, Na Slupi 4, Prague, Czech Republic; ${ }^{15}$ Rheumatology Unit, Department of Clinical and Experimental Medicine, University of Padova, Padova, Italy;

${ }^{16}$ Rheumatology Unit, Federal Institute for Drugs and Medical Devices, Bonn, Germany; ${ }^{17}$ 2nd Department of Medicine, Krankenhauz Lainz, Vienna, Austria;

${ }^{18}$ Department of Rheumatology, Ghent University Hospital, Gent, Belgium;

${ }^{19}$ Department of Radiology, Leiden University Medical Centre, Leiden, The

Netherlands; ${ }^{20}$ Department of Rheumatology, Rehabilitation and Internal Medicine, University of Medical Sciences, Poznan, Poland

Table 6 Future research agenda for diagnosis of hand osteoarthritis (HOA)

\begin{tabular}{|c|c|}
\hline No. & Proposition \\
\hline 1 & $\begin{array}{l}\text { The relative utility of imaging techniques (plain } x \text { rays, MRI, ultrasonography, scintigraphy) in early diagnosis and evaluation of progression of the HOA subsets needs to } \\
\text { be determined. }\end{array}$ \\
\hline 2 & Risk factors for development and long-term clinical outcome of the different subsets of HOA need to be determined. \\
\hline 3 & $\begin{array}{l}\text { Potential biomarkers of bone, cartilage, synovium and inflammation should be examined in HOA subsets for utility in terms of early diagnosis, assessment of disease } \\
\text { activity and prediction of outcome. }\end{array}$ \\
\hline 4 & Diagnostic and classification criteria to better define $\mathrm{HOA}$ and its subsets need to be developed and validated. \\
\hline 5 & $\begin{array}{l}\text { Further studies are required to confirm the associations between HOA and systemic risk factors such as menopausal state, bone density, obesity and metabolic } \\
\text { syndrome, and to explain the mechanisms that underlie such associations. }\end{array}$ \\
\hline 6 & The genetic factors that predispose to the different phenotypes of HOA need to be identified. \\
\hline 7 & The population incidence and prevalence of $\mathrm{HOA}$ and its subtypes (symptomatic and asymptomatic), standardised by age and gender, need to be confirmed. \\
\hline 8 & $\begin{array}{l}\text { Studies should be undertaken to determine whether erosive HOA is a discrete subset with specific risk factors and pathogenesis, or a subgroup of HOA with a worse } \\
\text { outcome. }\end{array}$ \\
\hline 9 & The association between the different HOA phenotypes and large joint $\mathrm{OA}$ (ie generalised $\mathrm{OA}$ ) needs further examination. \\
\hline
\end{tabular}


Acknowledgements: The authors would like to thank the European League Against Rheumatism for financial support, Helen Richardson for logistical support, Jane Robertson for literature search and database development and Helen Myers and Michelle Marshall for assistance in the general search.

Funding: Financial support was received from the European League Against Rheumatism.

Competing interests: None declared.

\section{REFERENCES}

1. Cushnaghan J, Dieppe P. Study of 500 patients with limb joint osteoarthritis. 1 Analysis by age, sex, and distribution of symptomatic joint sites. Ann Rheum Dis 1991;50:8-13

2. Mannoni A, Briganti MP, Di Bari M, Ferrucci L, Costanzo S, Serni U, et al. Epidemiological profile of symptomatic osteoarthritis in older adults: a population based study in Dicomano, Italy. Ann Rheum Dis 2003;62:576-8.

3. Fickert S, Puhl W, Gunther KP. Epidemiology of generalised osteoarthritis. Aktuelle Rheumatologie 2003;28:302-7.

4. Dougados M, Nakache JP, Gueguen A. Criteria for generalized and focal osteoarthritis. Revue du Rhumatisme 1996:63:569-75.

5. Dahaghin S, Bierma-Zeinstra SMA, Reijman M, Pols HAP, Hazes JMW, Koes BW Does hand osteoarthritis predict future hip or knee osteoarthritis? Arthritis Rheum 2005:52:3520-7.

6. Zhang Y, Niu J, Kelly-Hayes M, Chaisson CE, Aliabadi P, Felson DT. Prevalence of symptomatic hand osteoarthritis and its impact on functional status among the elderly: the Framingham study. Am J Epidemiol 2002;156:S225.

7. Dahaghin S, Bierma-Zeinstra SMA, Reijman M, Pols HAP, Hazes JMW, Koes BW. Prevalence and determinants of one month hand pain and hand related disability in the elderly (Rotterdam study). Ann Rheum Dis 2005;64:99-104.

8. Altman R, Alarcon G, Appelrouth D, Bloch D, Borenstein D, Brandt K, et al. The American College of Rheumatology criteria for the classification and reporting of osteoarthritis of the hand. Arthritis Rheum 1990;33:1601-10.

9. Campion G, Dieppe P, Watt I. Heberden's nodes in osteoarthritis and rheumatoid arthritis. BMJ 1983;287:1512

10. Hart $\mathbf{D}$, Spector T, Egger $\mathrm{P}$, Coggon D, Cooper C. Defining osteoarthritis of the hand for epidemiological studies: the Chingford study. Ann Rheum Dis 1994;53:220-3.

11. Hart DJ, Spector TD, Brown P, Wilson P, Doyle DV, Silman AJ. Clinical signs of early osteoarthritis: reproducibility and relation to $x$ ray changes in 541 women in the general population. Ann Rheum Dis 1991;50:467-70.

12. Jordan KM, Arden NK, Doherty M, Bannwarth B, Bijlsma JW, Dieppe P, et al. EULAR recommendations 2003: an evidence based approach to the management of knee osteoarthritis: report of a task force of the Standing Committee for International Clinical Studies Including Therapeutic Trials (ESCISIT). Ann Rheum Dis 2003;62:1145-55.

13. Pendleton A, Arden N, Dougados M, Doherty M, Bannwarth B, Bijlsma JW, et al. EULAR recommendations for the management of knee osteoarthritis: report of a task force of the Standing Committee for International Clinical Studies Including Therapeutic Trials (ESCISIT). Ann Rheum Dis 2000;59:936-44.

14. Zhang W, Doherty M, Arden N, Bannwarth B, Bijlsma J, Gunther KP, et al. EULAR evidence based recommendations for the management of hip osteoarthritis: report of a task force of the EULAR Standing Committee for International Clinical Studies Including Therapeutics (ESCISIT). Ann Rheum Dis 2005:64:669-81.

15. Zhang W, Doherty M, Leeb BF, Alekseeva L, Arden NK, Bijlsma JW, et al. EULAR evidence based recommendations for the management of hand osteoarthritis: report of a task force of the EULAR Standing Committee for International Clinical Studies Including Therapeutics (ESCISIT). Ann Rheum Dis 2007;66:377-88.

16. Dougados M, Betteridge N, Burmester GR, Euller-Ziegler L, Guillemin F, Hirvonen J, et al. EULAR standardised operating procedures for the elaboration, evaluation, dissemination, and implementation of recommendations endorsed by the EULAR standing committees. Ann Rheum Dis 2004;63:1172-6.

17. Zhang W, Doherty M, Pascual E, Bardin T, Barskova V, Conaghan P, et al. EULAR evidence based recommendations for gout. Part I: Diagnosis. Report of a task force of the standing committee for international clinical studies including therapeutics (ESCISIT). Ann Rheum Dis 2006;65:1301-11.

18. Whitehead A, Whitehead J. A general parametric approach to the meta-analysis of randomized clinical trials. Statistics Med 1991;10:1665-77.

19. Deeks JJ, Altman DG. Diagnostic tests 4: likelihood ratios. BMJ 2004;329:168-9.

20. Altman DG, Bland JM. Statistics notes: diagnostic tests 3: receiver operating characteristic plots. BMJ 1994;309:188.

21. Kleinbaum DG, Kuppler LL, Morgenstern H. Epidemiologic research - principles and quantitative methods. Chichester, UK: John Wiley \& Sons, Inc, 1982.

22. Srikanth VK, Fryer JL, Zhai G, Winzenberg TM, Hosmer D, Jones G. A metaanalysis of sex differences prevalence, incidence and severity of osteoarthritis. Osteoarthritis Cartilage 2005;13:769-81.

23. Oliveria SA, Felson DT, Reed JI, Cirillo PA, Walker AM. Incidence of symptomatic hand, hip, and knee osteoarthritis among patients in a health maintenance organization. Arthritis Rheum 1995;38:1134-41.

24. Butler WJ, Hawthorne VM, Mikkelsen WM, Carman WJ, Bouthillier DL, Lamphiear $\mathrm{DE}$, et al. Prevalence of radiologically defined osteoarthritis in the finger and wrist joints of adult residents of Tecumseh, Michigan, 1962-65. J Clin Epidemiol 1988:41:467-73.
25. Cooper C, Egger P, Coggon D, Hart DJ, Masud T, Cicuttini F, et al. Generalized osteoarthritis in women: pattern of joint involvement and approaches to definition for epidemiological studies. J Rheumatol 1996;23:1938-42.

26. Haara MM, Heliovaara M, Kroger H, Arokoski JPA, Manninen P, Karkkainen A, et al. Osteoarthritis in the carpometacarpal joint of the thumb: Prevalence and associations with disability and mortality. J Bone Joint Surg 2004;86:1452-7.

27. Wilder FV, Barrett JP, Farina EJ. Joint-specific prevalence of osteoarthritis of the hand. Osteoarthritis Cartilage 2006;14:953-7.

28. Dahaghin S, Bierma-Zeinstra SMA, Ginai AZ, Pols HAP, Hazes JMW, Koes BW. Prevalence and pattern of radiographic hand osteoarthritis and association with pain and disability (the Rotterdam study). Ann Rheum Dis 2005;64:682-7.

29. Lawrence JS. Rheumatism in cotton operatives. Br J Industry Med 1961:18:270-6.

30. Jensen $\mathbf{V}$, Boggild $H$, Johansen JP. Occupational use of precision grip and forceful gripping, and arthrosis of finger joints: a literature review. Occup Med 1999;49:383-8.

31. Lawrence JS, Bremner JM, Bier F. Osteo-arthrosis. Prevalence in the population and relationship between symptoms and $x$ ray changes. Ann Rheum Dis 1966;25:1-24.

32. Erb A, Brenner H, Gunther KP, Sturmer T. Hormone replacement therapy and patterns of osteoarthritis: baseline data from the Ulm Osteoarthritis Study. Ann Rheum Dis 2000;59:105-9.

33. Spector TD, Nandra D, Hart DJ, Doyle DV. Is hormone replacement therapy protective for hand and knee osteoarthritis in women?: the Chingford study. Ann Rheum Dis 1997:56:432-4.

34. Cooley HM, Stankovich J, Jones G. The association between hormonal and reproductive factors and hand osteoarthritis. Maturitas 2003:45:257-65.

35. Maheu E, Dreiser R-L, Guillou GB, Dewailly J. Hand osteoarthritis patients characteristics according to the existence of a hormone replacement therapy. Osteoarthritis Cartilage 2000:8:S33-7.

36. Haara MM, Arokoski JPA, Kroger H, Karkkainen A, Manninen P, Knekt P, et al. Association of radiological hand osteoarthritis with bone mineral mass: a population study. Rheumatology 2005;44:1549-54.

37. Hochberg MC, Lethbridge-Cejku M, Scott WW Jr, Plato CC, Tobin JD. Appendicular bone mass and osteoarthritis of the hands in women: data from the Baltimore longitudinal study of aging. J Rheumatol 1994;21:1532-6.

38. Marcelli C, Favier F, Kotzki PO, Ferrazzi V, Picot MC, Simon L. The relationship between osteoarthritis of the hands, bone mineral density, and osteoporotic fractures in elderly women. Osteoporosis Int 1995;5:382-8.

39. Schneider DL, Barrett-Connor E, Morton DJ, Weisman M. Bone mineral density and clinical hand osteoarthritis in elderly men and women: the Rancho Bernardo study. J Rheumatol 2002;29:1467-72.

40. Sowers M, Hochberg M, Crabbe JP, Muhich A, Crutchfield M, Updike S. Association of bone mineral density and sex hormone levels with osteoarthritis and the hand and knee in premenopausal women. Am J Epidemiol 1996;143:38-47.

41. Jonsson H, Manolescu I, Stefansson SE, Ingvarsson T, Jonsson HH, Manolescu A, et al. The inheritance of hand osteoarthritis in Iceland. Arthritis Rheum 2003;48:391-5.

42. Riyazi N, Meulenbelt I, Kroon HM, Ronday KH, Hellio LG, Rosendaal FR, et al. Evidence for familial aggregation of hand, hip, and spine but not knee osteoarthritis in siblings with multiple joint involvement: The GARP study. Ann Rheum Dis 2005; 64:438-43.

43. Spector TD, MacGregor AJ. Risk factors for osteoarthritis: genetics. Osteoarthritis Cartilage 2004;12(Suppl):44

44. Zhang W, Doherty M. How important are genetic factors in osteoarthritis? Contributions from family studies. J Rheumatol 2005;32:1139-42.

45. Bagge E, Bjelle A, Eden S, Svanborg A. Factors associated with radiographic osteoarthritis: results from the population study 70 -year-old people in Goteborg. $J$ Rheumatol 1991;18:1218-22.

46. Carman WJ, Sowers M, Hawthorne VM, Weissfeld LA. Obesity as a risk factor for osteoarthritis of the hand and wrist: a prospective study. Am J Epidemiol 1994:139:119-29.

47. Cicuttini FM, Baker JR, Spector TD. The association of obesity with osteoarthritis of the hand and knee in women: a twin study. J Rheumatol 1996;23:1221-6.

48. Haara MM, Manninen P, Kroger H, Arokoski JP, Karkkainen A, Knekt P, et al. Osteoarthritis of finger joints in Finns aged 30 or over: prevalence, determinants, and association with mortality. Ann Rheum Dis 2003;62:151-8.

49. Oliveria SA, Felson DT, Cirillo PA, Reed JI, Walker AM. Body weight, body mass index, and incident symptomatic osteoarthritis of the hand, hip, and knee. Epidemiology 1999:10:161-6.

50. Chaisson CE, Zhang Y, Sharma L, Kannel W, Felson DT. Grip strength and the risk of developing radiographic hand osteoarthritis: results from the Framingham study. Arthritis Rheum 1999:42:33-8.

51. Huskisson EC, Dieppe PA, Tucker AK, Cannell LB. Another look at osteoarthritis Ann Rheum Dis 1979;38:423-8.

52. Niu J, Zhang Y, La Valley M, Chaisson CE, Aliabadi P, Felson DT. Symmetry and clustering of symptomatic hand osteoarthritis in elderly men and women: the Framingham study. Rheumatology 2003:42:343-8.

53. Plato CC, Norris AH. Osteoarthritis of the hand: age-specific joint-digit prevalence rates. Am J Epidemiol 1979;109:169-80.

54. Chaisson CE, Zhang Y, McAlindon TE, Hannan MT, Aliabadi P, Naimark A, et al. Radiographic hand osteoarthritis: Incidence, patterns, and influence of pre-existing disease in a population based sample. J Rheumatol 1997:24:1337-43.

55. Poole J, Sayer AA, Hardy R, Wadsworth M, Kuh D, Cooper C. Patterns of interphalangeal hand joint involvement of osteoarthritis among men and women: a British cohort study. Arthritis Rheum 2003:48:3371-6. 
56. Egger P, Cooper C, Hart DJ, Doyle DV, Coggon D, Spector TD. Patterns of joint involvement in osteoarthritis of the hand: the Chingford study. J Rheumatol 1995;22:1509-13.

57. Neame R, Zhang W, Deighton C, Doherty M, Doherty S, Lanyon P, et al. Distribution of radiographic osteoarthritis between the right and left hands, hips, and knees. Arthritis Rheum 2004;50:1487-94

58. Caspi D, Flusser G, Farber I, Ribak J, Leibovitz A, Habot B, et al. Clinical, radiologic, demographic, and occupational aspects of hand osteoarthritis in the elderly. Semin Arthritis Rheum 2001;30:321-31.

59. Cicuttini FM, Baker J, Hart DJ, Spector TD. Relation between Heberden's nodes and distal interphalangeal joint osteophytes and their role as markers of generalised disease. Ann Rheum Dis 1998;57:246-8.

60. Thaper A, Zhang W, Wright G, Doherty M. Relationship between Heberden's nodes and underlying radiographic changes of osteoarthritis. Ann Rheum Dis 2005:64:1214-6.

61. Dreiser R-L, Maheu E, Guillou GB, Caspard H, Grouin J-M. Validation of an algofunctional index for osteoarthritis of the hand. Revue du Rhumatisme 1995:62:43S-53S

62. Kjeken I, Dagfinrud H, Slatkowsky-Christensen B, Mowinckel P, Uhlig T, Kvien TK, et al. Activity limitations and participation restrictions in women with hand osteoarthritis: patients' descriptions and associations between dimensions of functioning. Ann Rheum Dis 2005;64:1633-8.

63. Ricci JA, Stewart WF, Chee E, Leotta C, Foley K, Hochberg MC. Pain exacerbation as a major source of lost productive time in US workers with arthritis. Arthritis Rheum 2005;53:673-81

64. Jones G, Cooley HM, Bellamy N. A cross-sectional study of the association between Heberden's nodes, radiographic osteoarthritis of the hands, grip strength, disability and pain. Osteoarthritis Cartilage 2001;9:606-11.

65. Bagis S, Sahin G, Yapici Y, Cimen OB, Erdogan C. The effect of hand osteoarthritis on grip and pinch strength and hand function in postmenopausal women. Clin Rheumatol 2003;22:420-4

66. Pattrick M, Aldridge S, Hamilton E, Manhire A, Doherty M. A controlled study of hand function in nodal and erosive osteoarthritis. Ann Rheum Dis 1989;48:978-82.

67. Leeb BF, Sautner J, Andel I, Rintelen B. SACRAH: a score for assessment and quantification of chronic rheumatic affections of the hands. Rheumatology 2003;42:1173-8.

68. Ziebland S, Fitzpatrick R, Jenkinson C, Mowat A, Mowat A. Comparison of two approaches to measuring change in health status in rheumatoid arthritis: the Health Assessment Questionnaire (HAO) and modified HAO. Ann Rheum Dis 1992;51:1202-5.

69. Backman C, Mackie H. Arthritis hand function test: inter-rater reliability among self-trained raters. Arthritis Care Res 1995:8:10-5.

70. Meenan RF, Mason JH, Anderson JJ, Guccione AA, Kazis LE. AIMS2. The content and properties of a revised and expanded Arthritis Impact Measurement Scales Health Status Questionnaire. Arthritis Rheum 1992/35·1-10.

71. Duruoz MT, Poiraudeau S, Fermanian J, Menkes CJ, Amor B, Dougados M, et al. Development and validation of a rheumatoid hand functional disability scale that assesses functional handicap. J Rheumatol 1996:23:1167-72.

72. Sautner J, Andel I, Rintelen B, Leeb BF. Development of the M-SACRAH, a modified, shortened version of SACRAH (Score for the Assessment and Quantification of Chronic Rheumatoid Affections of the Hands). Rheumatology 2004:43:1409-13.

73. Bellamy N, Campbell J, Haraoui B, Gerecz-Simon E, Buchbinder R, Hobby K, et al. Clinimetric properties of the AUSCAN osteoarthritis hand index: an evaluation of reliability, validity and responsiveness. Osteoarthritis Cartilage 2002;10:863-9.

74. Dziedzic KS, Thomas E, Hay EM. A systematic search and critical review of measures of disability for use in a population survey of hand osteoarthritis (OA). Osteoarthritis Cartilage 2005;13:1-12.

75. Englund M, Paradowski PT, Lohmander LS. Association of radiographic hand osteoarthritis with radiographic knee osteoarthritis after meniscectomy. Arthritis Rheum 2004;50:469-75

76. Hochberg MC, Lane NE, Pressman AR, Genant HK, Scott JC, Nevitt M. The association of radiographic changes of osteoarthritis of the hand and hip in elderly women. J Rheumatol 1995;22:2291-4.

77. Mannoni A, Briganti MP, Di Bari M, Ferrucci L, Serni U, Masotti G, et al. Prevalence of symptomatic hand osteoarthritis in community-dwelling older persons: The ICARe Dicomano study. Osteoarthritis Cartilage 2000;8:S11-S13.
78. Jonsson H, Valtysdottir ST, Kjartansson O, Brekkan A. Hypermobility associated with osteoarthritis of the thumb base: A clinical and radiological subset of hand osteoarthritis. Ann Rheum Dis 1996;55:540-3

79. Kraus VB, Li YJ, Martin ER, Jordan JM, Renner JB, Doherty M, et al. Articular hypermobility is a protective factor for hand osteoarthritis. Arthritis Rheumatism 2004;50:2178-83.

80. Spacek E, Poiraudeau S, Fayad F, Lefevre-Colau MM, Beaudreuil J, Rannou F, et al Disability induced by hand osteoarthritis: are patients with more symptoms at digits 2-5 interphalangeal joints different from those with more symptoms at the base of the thumb? Osteoarthritis Cartilage 2004;12:366-73.

81. Smith D, Braunstein EM, Brandt KD, Katz BP. A radiographic comparison of erosive osteoarthritis and idiopathic nodal osteoarthritis. J Rheumatol 1992;19:896-904.

82. Verbruggen G, Goemaere S, Veys EM. Systems to assess the progression of finger joint osteoarthritis and the effects of disease modifying osteoarthritis drugs. Clin Rheumatol 2002;21:231-43

83. Verbruggen G, Veys EM. Erosive and non-erosive hand osteoarthritis. Use and limitations of two scoring systems. Osteoarthritis Cartilage 2000;8:S45-S54.

84. Cobby M, Cushnaghan J, Creamer P, Dieppe P, Watt I. Erosive osteoarthritis: is it a separate disease entity? Clin Radiol 1990;42:258-63.

85. Fioravanti A, Tofi C, Cerase A, Priolo F, Marcolongo R. Capillaroscopic findings in erosive and nodal osteoarthritis of the hands. Clin Rheumatol 2001;20:174-6.

86. Punzi L, Ramonda R, Oliviero F, Sfriso P, Mussap M, Plebani M, et al. Value of C reactive protein in the assessment of erosive osteoarthritis of the hand. Ann Rheum Dis 2005:64:955-7.

87. Silvestri T, Pulsatelli L, Dolzani P, Punzi L, Meliconi R. Analysis of cartilage biomarkers in erosive and non-erosive osteoarthritis of the hands. Osteoarthritis Cartilage 2004;12:843-5.

88. Rovetta G, Battista S, Brignone A, Monteforte P. Quantitative ultrasound of the proximal phalanges: reproducibility in erosive and nodal osteoarthritis of the hands. Int J Tissue React 1999;21:121-7.

89. Riestra JL, Sanchez A, Rodriques-Valverde V. Roentgenographic features of the arthropathy associated with CPPD crystal deposition disease. A comparative study with primary osteoarthritis. J Rheumatol 1985:12:1154-8.

90. Fam AG, Stein J, Rubenstein J. Gouty arthritis in nodal osteoarthritis. J Rheumatol 1996:23:684-9.

91. Gerster JC, Rappoport G, Ginalski JM. Prevalence of periarticular calcifications in pyrophosphate arthropathy and their relation to nodal osteoarthritis. Ann Rheum Dis 1984;43:255-7.

92. Erturk H, Bal S, Aydin M, Ugur 0, Celiker R. The predictive value of bone scintigraphy in osteoarthritis relationship with age and severity of the disease. J Rheumatol Med Rehab 2002:13:25-9.

93. Falsetti P, Frediani B, Fioravanti A, Acciai C, Baldi F, Filippou G, et al. Sonographic study of calcaneal entheses in erosive osteoarthritis, nodal osteoarthritis, rheumatoid arthritis and psoriatic arthritis. Scand J Rheumatol 2003;32:229-34

94. Tan AL, Grainger AJ, Tanner SF, Shelley DM, Pease C, Emery P, et al. Highresolution magnetic resonance imaging for the assessment of hand osteoarthritis. Arthritis Rheum 2005; 52:2355-65

95. Tan AL, Grainger AJ, Tanner SF, Emery P, McGonagle D. A high-resolution magnetic resonance imaging study of distal interphalangeal joint arthropathy in psoriatic arthritis and osteoarthritis: are they the same? Arthritis Rheum 2006:54:1328-33.

96. Kessler S, Dieppe P, Fuchs J, Sturmer T, Gunther KP. Assessing the prevalence of hand osteoarthritis in epidemiological studies. The reliability of a radiological hand scale. Ann Rheum Dis 2000;59:289-92.

97. Bellamy N, Klestov A, Muirden K, Kuhnert P, Do KA, O'Gorman L, et al. Perceptual variation in categorizing individuals according to American College of Rheumatology classification criteria for hand, knee, and hip osteoarthritis $(0 \mathrm{~A})$ : observations based on an Australian twin registry study of OA. J Rheumatol 1999:26:2654-8.

98. Maheu E, Cadet C, Gueneugues S, Ravaud P, Dougados M. Reproducibility and sensitivity to change of four scoring methods for the radiological assessment of osteoarthritis of the hand. Ann Rheum Dis 2007:66:464-9.

99. McCarthy C, Cushnaghan J, Dieppe P. The predictive role of scintigraphy in radiographic osteoarthritis of the hand. Osteoarthritis Cartilage 1994;2:25-8.

100. Zhang W, Doherty M. EULAR recommendations for knee and hip osteoarthritis: a critique of the methodology. Br J Sports Med 2006;40:664-9. 